\title{
Distilling the essence of general practice: a learning journey in progress
}

\author{
John CM Gillies, Stewart W Mercer, Andrew Lyon, Mairi Scott and Graham CM Watt
}

\begin{abstract}
Over the past 5 years, general practice in the UK has undergone major change. Starting with the introduction of the new GMS contract in 2004, it has continued apace with the establishment of Postgraduate Medical Education Training Board, a GP training curriculum, and nMRCGP. The NHS is developing very differently in the four countries of the UK. Regulation of the profession is under review, and a system of relicensing, recertification, and revalidation is being introduced. The Essence project, initiated by RCGP Scotland in conjunction with International Futures Forum 4 years ago is a constructive response to these changes. It has included learning journeys, a discussion day for GPs, and commissioned short pieces of 100 words from GPs and patients. From an analysis of these, some characteristics of the essence of general practice have been defined. These include key roles and core personal qualities for GPs. It is argued that general practice has important and unique advantages - trust, coordination, continuity, flexibility, universal coverage, and leadership - which mean that it should continue to be central to the development of primary care throughout the UK. Keywords

family medicine; general practice; values.
\end{abstract}

JCM Gillies, MA, FRCGP, FRCPE, GP, Selkirk Health Centre, Selkirk, associate adviser, GP Training Unit, Lister Institute, Edinburgh, and honorary senior lecturer, Department of General Practice, University of Edinburgh, Edinburgh. SW Mercer, PhD, FRCGP, professor of primary care research; GCM Watt, MD, FRCGP, FMedSci, professor of general practice, Department of General Practice and Primary Care, Division of Communitybased Sciences, University of Glasgow, Glasgow. A Lyon, MA, $P h D$, Converger, International Futures Forum, The Boathouse, Aberdour, Fife. M Scott, FRCGP, FRCPE, FHEA Royal College of General Practitioners (Scotland), Edinburgh, and Professional Development Academy, Tayside Centre of General Practice, University of Dundee, Dundee.

Address for correspondence

Dr John Gillies, Selkirk Health Centre, Viewfield Lane, Selkirk TD7 4LQ, Scotland. E-mail: j.gillies@rural-health.ac.uk

Submitted: 4 December 2008; Editor's response: 6 January 2009; final acceptance: 3 February 2009.

@British Journal of General Practice

This is the full-length article of an abridged version published in print. Cite this article as: $\mathrm{Br} J$ Gen Pract 2009; DOI: 10.3399/bjgp09X420626.
'The dogmas of the quiet past are inadequate to the stormy present. The occasion is piled high with difficulty. As our case is new, we must think anew and act anew.' (Abraham Lincoln)

\section{INTRODUCTION: BACKGROUND TO THE JOURNEY}

'Essence: that which constitutes the being of a thing; that by which it is what it is.' (Oxford English Dictionary, page 896.)

General practice as a discipline has made considerable strides forward over the past three decades. There is good evidence that welldeveloped general practice and primary care systems can improve quality of care within a health system. ${ }^{1}$ The discipline of general practice has been closely examined and defined, ${ }^{2}$ and in the UK a training curriculum proposed by the Royal College of General Practitioners (RCGP) ${ }^{3}$ has been approved by the Postgraduate Medical Education Training Board (PMETB). ${ }^{4}$ A new entry examination, nMRCGP, based on the new curriculum, has been established. The new general medical services (nGMS) contract is largely evidence based, ${ }^{5}$ in that most of the targeted areas within the Quality and Outcomes Framework (QOF) are directly or indirectly supported by evidence from randomised controlled trials and, if achieved, are expected to improve individual and population health. Contrary to expectations, practices have responded to its introduction by achieving high scores in the QOF. This development, unique in general practice, is being watched with interest in many other countries. ${ }^{6}$

Although the QOF covers many important aspects of care, GPs also recognise that the inherent strength and complexity of the doctor-patient relationship supports quality at a much deeper level. ${ }^{7,8}$ There are growing anxieties that the focus on the QOF, driven by financial incentives, may lead to the loss of something important but hard to measure in general practice. ${ }^{8-11}$ This is an unsettling environment for patients and doctors. In addition, recent devolution and political changes in the UK mean that four widely 
different NHSs are emerging, in Scotland, England, Wales, and Northern Ireland. While each of them is still founded on Bevan's philosophy, the four countries of the UK have increasingly different approaches and institutional frameworks to deliver health services. ${ }^{12,13}$ With a nationalist government in Scotland and a clear move towards privatisation and disaggregation of the NHS in England, this divergence is likely to increase over the next few years. There are also many other changes in society and within the profession that challenge the current position of general practice. Some of these are summarised in Box 1.

This divergence in policy and delivery makes it even more important that GPs and patients try to define and enhance the 'essence' of general practice lest it becomes lost in the plethora of changing organisational structures that characterise the NHS today. This paper is an attempt not to preserve or maintain a mythical 'golden age', but to look critically at current developments, explore ideas, and suggest possible ways forward for general practice that both provide continuity with past traditions and engage constructively with the rapidly changing worlds of evidence, technology, and contemporary culture. In doing so, it was hoped that some characteristics of the essence of general practice would be defined.

Conventional responses may be inadequate in helping the profession to respond effectively to this continuing and unpredictable change. Because of this, a collaboration has been formed with the International Futures Forum (IFF) (a non-profit organisation 'that exists to develop the capacity to sustain human aspiration, realised through wise action, in a complex and challenging world'). ${ }^{14}$ Novel methods have been employed, and previously piloted to examine public health in Scotland, ${ }^{15}$ to look critically at current developments.

The methodology has included learning journeys, a discussion day, and commissioned short pieces of 100 words from GPs and patients. It began by asking, through learning journeys (Figure 1): how are we addressing the complexity, change, and uncertainty of early 21 st century general practice?

\section{FIRST STEPS ON THE JOURNEY}

Two learning journeys were carried out and a discussion day was held. Detailed information on the process is available in Appendix 1. The first was for members of the group who visited two sites: a day centre for the over 50s in an urban area of high deprivation, which had thrived through a period when many better-funded, similar organisations had failed, and a large national organisation which was subject to both market forces and considerable government oversight and regulation.

\section{How this fits in}

Over the past 10 years, general practice in the UK has undergone major changes in education and training, workforce characteristics, and contractual arrangements. These have occurred against a background of rapid societal change, and produced uncertainty and a feeling of loss among many GPs. There is little published literature looking critically at the consequences of these current developments and so exploring the core values of general practice with an emphasis on the future. This study uses innovative methodology to examine this area. From this work important key roles for future GPs have been derived and a summary of personal qualities required. This study suggests that general practice should continue to be central to the development of health care because only general practice offers the key advantages of trust, coordination, continuity, flexibility, universal coverage, and leadership. Challenges for GPs include that of retaining their role in changing times, raising quality across the whole of the GP spectrum, and grasping the potential for leadership that is now being presented.

The second learning journey was organised for GP registrars and trainers based in a Scottish deanery. The aim was to use these journeys as a basis for reflection on what GPs do and how they should be trained in future. The three locations chosen were the Homeless World Cup Centre, ${ }^{16}$ the human resources

\section{Box 1. Some forces affecting general practice today.}

\section{Society}

- Economism

- Individualism

Rapid change, uncertainty, increasing complexity

Rise in consumerism

- Decline in medical paternalism

- Use of the internet for information on health and disease

- Attacks on professionalism as a societal good

Rise in managerialism/contractualism

- Rise in use of complementary medicine

Loss of belief in transcendent values

- Intolerance of uncertainty

Blame culture/culture of suspicion

General practice

Geographical mobility of patients/doctors

- Multidisciplinary working

- Male to female ratio shift in workforce

- Change in attitudes to work-life balance issues

- Regulatory/General Medical Council changes: relicensing, recertification, revalidation

Rise in state paternalism (public health drivers in nGMS) 


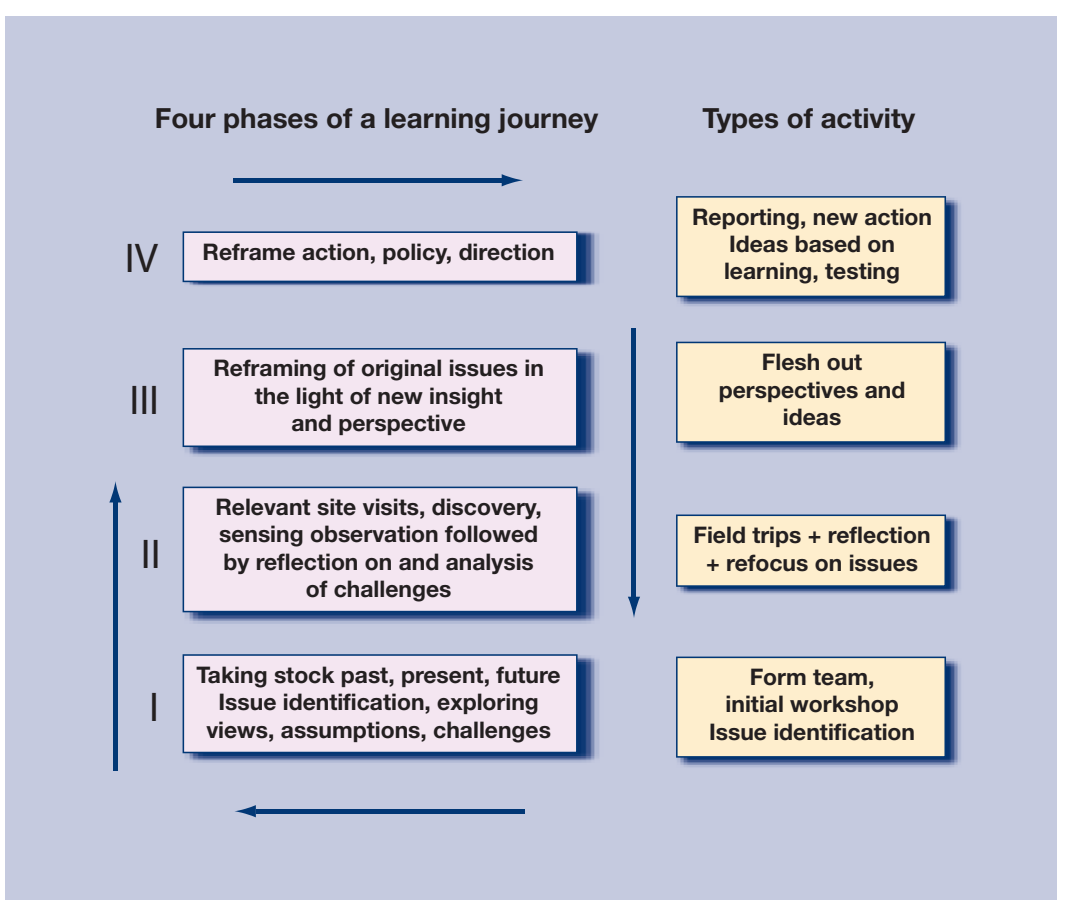

Figure 1. Phases of a learning journey (Appendix 1 for more detail).

division of a large NHS Scotland organisation, and the telephone banking division of a major UK bank. Extensive contemporaneous notes were made and circulated among the learning journey participants. Feedback and further discussion refined the material. The main learning points are summarised in Box 2 .

\section{DISCUSSION DAY ON THE ESSENCE OF GENERAL PRACTICE}

This all-day meeting, organised to encourage freedom of expression and frank discussion, ${ }^{17}$ was organised by IFF in association with the section of General Practice and Primary Care, University of Glasgow, and RCGP Scotland. Full details on the process and analysis are in Appendix 2. Forty invited GPs, a psychologist, and a poet took part. Most of the day was spent exploring issues in small, often impassioned, groups. In addition a series of $16100-$ word summaries on the future of general practice, obtained from prominent GPs, was circulated to

\section{Box 2. Lessons from the learning journeys.}

- Success in a small organisation depends on sustaining clear direction through periods of turbulent change.

- Morale and sometimes survival depend on leadership.

- In caring organisations, people - employees, trainees, volunteers respond to altruism in their leaders.

- There is a need to listen closely to trainees, not just about training competencies and career structures, but to their need for discourse on core values.

When values are unclear, standards will inevitably fall. participants prior to the meeting, and attached to the walls of the room to stimulate discussion. Following the meeting, the patient group of RCGP Scotland was asked for a similar series of 100 words. The full text of all 25 statements is available as a set of prompt cards, developed as learning tools for GPs. ${ }^{18}$

\section{LEARNING FROM THE JOURNEY}

The fact that the NHS still provides contact, universal coverage, and a variable degree of continuity, without financial barriers for patients, was regarded as a major achievement. However, the 'inverse care law' still persists. ${ }^{19,20}$ The rapid and repeated organisational change that has characterised the NHS for many years was felt to consume rather than generate energy, ${ }^{21}$ often undermining creative initiatives in general practice before they had a chance to deliver. There was also concern that the $\mathrm{NHS}$ has become too risk-averse:

'All good learning embraces the possibility of failure, yet we persist in a culture that has at root the delusion that it is possible to develop failsafe, foolproof systems.' (GP)

There was also a widespread feeling that the NHS - large, bureaucratic, and slow to respond - fails to understand general practice - small, dispersed, and often engaged with local communities. ${ }^{22}$ There was a consensus that discussions on the future should reflect the GMS contract but that contracts should be used to enable rather than limit developments in general practice.

There is an unacknowledged tension between profit and service in general practice, which leads to difficult decisions over investment in staff and services. Successful adaptation to future challenges needs local GP leaders who have vision, and can see the opportunities ahead and respond in a way that does not compromise core values. Much discussion was generated by the visit to the Homeless World Cup Centre. ${ }^{16}$ This discussion related to what was seen as the under-realised potential of GPs to engage more fully, as social entrepreneurs, with communities, voluntary organisations, and other businesses. Obstacles to this were seen to be time and lack of incentivisation of this potential by NHS structures.

Extended teamwork was seen as essential to the functioning of a modern NHS, and general practice is well placed to be central to much of that. However, there were tensions between the need for effective teamwork and patients' wish to relate to and sometimes see their own GP, rather than another team member.

There was consensus that the advent of evidence- 
based medicine had transformed the clinical effectiveness of general practice, and that the evidence-based incentives in nGMS are likely to produce public health benefit, yet concern that certain individual patients may benefit little from this:

'Incentives do work: nGMS will save lives and produce better care, but drives the doctor's agenda, not the patient's.' (GP)

Concerns were also expressed around the status and use of the word 'evidence'. GPs work in a complex social system. Clinical judgment is often based on weighing different types of evidence. Evidence adds to understanding and clinical reasoning, but does not replace it. It was not seen as a simple and emphatic driver for the future of high-quality general practice.

Tension between a focus on interpersonal relationships and the increasing use and potentially dehumanising effects of information technology was a common theme throughout the project. Worries were also raised about the growing medicalisation of populations. There was also concern that registration with a practice rather than a GP was driving a twotier pay and power structure - powerful executive principals and younger subservient salaried partners, in which the latter felt disengaged, not valued, and at risk of exploitation.

\section{DEFINING THE ESSENCE OF GENERAL PRACTICE: THE JOURNEY CONTINUES}

Being a General Practitioner, the core statement of the nMRCGP curriculum, ${ }^{3}$ contains a daunting 75 learning outcomes for GP trainees. Concern was expressed by both registrars and trainers about whether it is possible to create, within a limited timebased training programme, a GP who is fully aware of and engaged with these outcomes. A further concern shared by trainees and trainers was the erosion of the traditional value base of general practice and the need for more discourse on core professional values in general practice training. This is reflected in the current debate about the meaning of generalism and how it should be reflected in a reductionist age. ${ }^{23}$

\section{ESSENTIAL FUTURE ROLES AND PERSONAL QUALITIES}

Box 3 summarises key roles for future GPs that were derived from analysis of the 100 words from GPs and patients. The consultation has been seen as the core of general practice for over 40 years. ${ }^{7}$ Unsurprisingly, the ability to deliver patient-centred care in the future, through high-quality consultations, was repeatedly endorsed by GPs and patients at the discussion day and in the 100-word statements.
'GPs must retain their sensitivity to patients' narratives; that advocacy for patients will save general practice.' (GP)

The ability to consult well was also implicit in the responses of patients to the question 'What do you value from your GP?'; these included:

'Being treated as an individual.'

‘I value my GP’s attention and time.’

'Gives me confidence to manage things myself.'

'Listens to suggestions I put forward regarding treatment for my condition'.

Qualities identified as required of a GP in the future included the following:

- robust intellect/passion for knowledge;

- altruism and commitment;

- awareness of justice;

- integrity;

- respect for patients;

- empathy/emotional awareness;

- capacity for innovation; and

- working with others.

General practice is a discipline in which the doctor-patient relationship is the active ingredient of almost everything that is achieved. ${ }^{24}$ In such a relationship, it is clear that the personal qualities of the doctor are complementary to clinical skills. The qualities identified by the learning journeys are closely reflected in the descriptors of medical professionalism in a recent Royal College of Physicians (London) report. ${ }^{25}$

\section{BACK TO THE FUTURE: DIRECTION, POLICY, ACTION}

The purpose in undertaking this project was to ask how, in the midst of frequent bureaucratic shifts and increasing service pressures, the essence of general

\section{Box 3. Key roles for future GPs.}

- Chronic disease management

- Prevention of ill-health

- Teaching colleagues/self

- Team working

- Holistic/personal care

- Continuity/coordinated care

Generalist 


\section{Box 4. Key advantages of general practice.}

- Trust: achieved by high-quality empathic communication with patients and past experience of good-quality care, ${ }^{30}$ essential for concordance with treatment, co-creation of health, effective gatekeeping, and avoidance of medicalisation. Underpinned by local perceptions of altruism, fair dealing and other personal qualities, competence, integrity, and probity, and by both a rhetoric and an assumption of good intentions. ${ }^{31}$

- Coordination: in dealing with patients' multiple problems and issues; between patients and relatives/partners, between GP and members of the primary healthcare team, social work, and voluntary agencies, between hospital consultant-led and primary care services.

- Continuity: generated by repeated contacts, developing and strengthening relationships with patients over months and years. Challenged by many trends, including the feminisation of general practice and new working patterns among GPs including daytime working, multiple providers of care, and GP-led health centres.

- Flexibility: to address problems in the order and at a pace that suits patients; adapting clinical evidence to the individual patient, nGMS contract requirements to local community needs; balancing individual and population approaches in day-to-day work; dealing capably with continuing NHS change; liaising effectively with local voluntary organisations; and innovating to good effect.

- Coverage: comprising over $90 \%$ contact with list populations over a 5-year period, including many who are 'hard to reach' using one-off screening approaches, so that special measures to enhance coverage are required for very few people. This cumulative approach to population coverage is much more sustainable than screening.

- Leadership: including the ability to implement change quickly, based on multidisciplinary knowledge and experience of local circumstances, staffing, and population characteristics.

practice can be explored and an attempt can be made to define it - those characteristics that are at its heart and central to its purpose and ethos, and that, therefore, should be of principal concern in shaping its future. It became obvious early in the course of this project that it was neither possible nor desirable to reach a one-sentence definition of the essence of general practice. However, through the learning journey process, roles were identified as well as personal qualities that are vital to high-quality general practice in the future. These personal qualities reflect the need for humanism, which is consistently identified as necessary for the future of general practice but often either marginalised or underexamined. ${ }^{26,27}$ In a rapidly changing international, national, and local context, the key activity of GPs must remain the clinical encounter. The consultation - and how and where it is provided - must be informed by research and evidence, ${ }^{26}$ guided by wisdom, and underpinned by values. The current tendency to reject the need for a broadly humanistic approach in favour of a narrow biomedical on ${ }^{28}$ needs to be challenged by both the academic and the working GP community, by exploring these aspects of general practice using the tools of narrative, anthropology, sociology, and philosophy. ${ }^{7,26,29}$ As well as this, in an ageing population with multiple morbidity becoming the norm rather than the exception, whole-system changes will be required to ensure that patients with complex physical, emotional, and social needs benefit from the holistic, continuous, and coordinated care required to improve individuals' and communities' health.

Although the direction of NHS policy appears to suggest that many functions of the GP can be performed by other professionals, including pharmacists and nurses, GPs are still uniquely trained, motivated, and situated, geographically, historically, and culturally to take forward this task in the 21st century. GPs of the future will require leadership skills, political vision, and a clear sense of purpose if they are to steer a primary care-led NHS towards achieving the worthy goals of its founders. The key advantages of general practice continuing to be central to the future development of primary care are summarised in Box 4.

\section{CONCLUSION}

The learning journeys and discussion day have been learning experiences for the authors of this paper as well as for all the participants. Based on the learning journeys, the analysis above, and subsequent reflections, three stark challenges face the discipline and threaten its future survival. The first challenge is to ensure that the blend of qualities, roles, and features that constitute the essence of general practice, as described above, remains the active ingredient of primary care and survives 'new arrangements' (in which GPs are likely to be required to work differently with almost everyone). The second challenge is to make this happen across the board and not just in leading-edge practices. The third, and the most important challenge, is the challenge of leadership by GPs rather than of GPs: in university departments, deaneries, professional bodies, and NHS management structures. This will be essential to maintain direction and momentum in the face of unsympathetic, antagonistic, and uncomprehending external forces. ${ }^{32}$ In the words of one GP participant, 'disengagement is a terrible prospect'. Will future GPs grasp the leadership nettle or leave this natural niche unfilled?

\section{Funding body}

We are grateful to RCGP (Scotland) and NHS Education Scotland for financial support

\section{Competing interests}

The authors have stated that there are none

Acknowledgements

We would like to thank all doctors and patients who contributed 100 word summaries and who attended and contributed thoughtfully to the learning journeys and discussion day. The '100-word' concept, central to the 


\section{COMMENTARY}

\section{Distributed intelligence - a different model for primary care}

In any complex system, information is collected, stored and acted on at many levels. If an organisation is going to be effective, these stocks of knowledge and flows of information have to be in the right place. In large organisations like the NHS, long-term strategic decision-making tends to be done at higher levels, where power tends to be more concentrated and widely disparate information can be collected and refined. Short-term tactical decision-making tends to be distributed to the periphery. Drawing the line between what is strategic and tactical in the right place is critically important and the more complex the periphery, the more of that decision making should be widely distributed.

In their article Gilles et al say that the NHS, 'fails to understand general practice [which is] small, dispersed, and often engaged with local communities." That is the point I want to address here.

USAF Colonel John Boyd developed a concept in the 1960s and 1970s for cold war era fighter combat that is helpful. His view was that fighter pilots would win dogfights if they could go through the loop of observation, orientation (and analysis) decision making, and action (OODA), more effectively than the enemy. Better OODA loops by fighter pilots became the goal of fighter design, pilot training, and every other decision process throughout Fighter Command. (OODA loops higher up the organisation were simply aimed at making pilot OODA loops more effective).

Later in life Boyd argued that driving power to the edge was critical to survival and success for most, large complex and adaptive organisations operating in uncertain, dynamic environments. The organisation's guiding imperative had to be to make edge teams as effective as possible. Objective-driven incentives should be used to influence resource requests and guide these edge team decisions, rather than resource allocation and method driven commands. In plain English, agree what they should do and then give them the support and the resources to do it.

In health delivery, the fighter pilot's type of responsibilities are shared between the primary healthcare delivery professionals and the person whose health is at issue. Together, they constitute the edge team. Knowledge of disease tends to be concentrated in the professional healthcare members of the team. Knowledge and control of the local terrain is more evenly distributed since the person at issue usually knows more about lifestyle and other environmental health determinants and can influence the course of disease through their engagement and determination.

Appropriate edge team composition and leadership shifts through a person's life. Normally, it is mostly just the person at issue - or their parent, in the case of minors - a team of one, supported by an informational and consultative network of public information, friends and family. As circumstances change, optimal team composition shifts to more participation from formal health services all the way through to circumstances where, of course, the team needs to be dominated by specialists.

In this vision of things, the GP's role is key. In many circumstances, that role is to be an effective team member - student, technician, facilitator, trainer, and guide. In other circumstances, that role is to lead - listening, directing, motivating, and setting the tone. Critically, the role can also include being a judge when changes in circumstance warrant a change in team dynamics or composition and when additional resources need to be deployed.

For health care to be effective in an environment of social and cultural change, of changes in medical knowledge, technology and disease, power has to be driven to the edge of the organisation. Edge teams have to be supported with the resources, the information and the intelligence they need to execute the best possible OODA loops. The distribution of intelligence has to be focused on sustained edge team effectiveness that lasts from birth to death.

In this dynamic environment, GPs are central: they have to be motivated toward excellence and empowered to understand, nurture, support and lead ever-changing excellence in those teams. The NHS has to learn to trust its GPs again.

\section{Charles Taylor}

Charles Taylor is a fellow of the Wharton Financial Institutions Center in Philadelphia and a specialist on governance, risk management, and public policy in the financial sector. His father, Lord Taylor of Harlow, was part of Nye Bevan's policy team that built the NHS after World War II and the author of Good General Practice, published by in 1954 by Oxford University Press. E-mail: Ctaylor@rmahq.org

\section{REFERENCE}

1. Gillies JCM, Mercer SW, Lyon A, et al. Distilling the essence of general practice: a learning journey in progress. Br J Gen Pract 2009; 59: el67-e176.

\section{DOI: 10.3399/bjgp09X420635}

process, was that of Professor Julian Tudor Hart. We would also like to thank Professor David Blaney, Dr Carey Lunan, Dr David Reilly, and Sharon Weiner-Ogilvie for ideas and analysis. Professors Kenneth Boyd and John Howie, and Drs Graham Buckley and Mike Porter contributed to the initial stages of the project. Ruth Wallace, Laura Kelleher, and Leanne Brown of RCGP (Scotland) have provided invaluable organisational support and advice.

\section{Discuss this article}

Contribute and read comments about this article on the Discussion Forum: http://www.rcgp.org.uk/bjgp-discuss

\section{REFERENCES}

1. Starfield B, Shi L, Macinko J. Primary care contributions to health systems and health. Milbank Q 2005; 83(3): 457-502. 


\section{COMMENTARY}

\section{Unintended consequences: what of quality outside the QOF?}

For over a decade general practice has been subject to increasing levels of governance, guidelines, incentives, and targets - what one professor of primary care has referred to as the 'industrialisation' of family medicine. ${ }^{1}$ A key step-change in this came with the introduction of the new GMS contract and Quality and Outcomes Framework (QOF) in 2004. For the first time, a significant proportion (typically around $20 \%$, but in some cases up to one-third) of general practice income was linked to performance - predominantly against biomedical indicators of quality of care, but also practice organisation, the provision of additional services and, to a lesser degree, attention to patient experience.

Gillies et al's learning journey reveals an underlying disquiet with such trends; and with the QOF in particular. ${ }^{2}$ While recognising the framework's potential to improve individual and population health, the authors cite 'growing anxieties that the focus on the QOF, driven by financial incentives, may lead to the loss of something important but hard to measure in general practice'. Their concerns are widespread and justified. ${ }^{3}$

Looking purely at biomedical indicators of quality included in the QOF, the evidence suggests that GPs have been working to higher standards since its introduction, and for some indicators a causal relationship is likely. General practice returned an average of $91.3 \%$ of the maximum possible score on the QOF in the first year (2004/05), rising to $96.8 \%$ in $2007 / 08$; significantly higher than was anticipated by the Department of Health. Concomitant with this there have been real step-changes in clinical quality for patients with certain chronic diseases, such as asthma and diabetes (though not $\mathrm{CHD}$ ); ${ }^{4}$ and inequality in practice performance has fallen, with faster improvement in practices in the most deprived quintile reducing the difference in relation to the least deprived from $4.0 \%$ to $0.88 \%{ }^{5}{ }^{5}$

However, as Gillies et al's study shows, there is more to general practice than simply hitting QOF targets: we should always be concerned with the net effect of the framework. Quality of care is hard to conceptualise and measure in ways which capture the full range of issues that matter to patients and can be applied day-to-day. While 'hard' endpoints of care are incredibly important, follow the framework too rigidly and the consultation soon becomes an inhuman exercise in ticking boxes, devoid of thought and feeling. The QOF does not (and could never) include all medical conditions and the way they present in individual patients; nor capture the essence of the consultation, and the relationship between doctor and patient. ${ }^{6}$ Unintended consequences from the QOF's biomedical focus were anticipated, and are in evidence.

For one, quality can be substantially worse for those with conditions outside the framework, particularly the older people with complex medical problems. In face-to-face interviews in the English Longitudinal Study of Ageing, $75 \%$ of responders reported receiving endorsed quality of care for conditions included in the QOF, compared with $58 \%$ for those not. ${ }^{7}$ And the gap is likely to be widening. Across 18 practices, achievement against 15 indicators concerning depression and osteoarthritis increased by just one percentage point from 35\% to 36\% between 2003 and 2005, compared with a 16 percentage point improvement in incentivised indicators relating to asthma and hypertension. ${ }^{8}$

More worrying, however, is the effect of the QOF on the wider patient-centred and holistic strengths of general practice. You can never perform the gold standard of randomised control trials on every kind of patient GPs meet every day of the week, so two things remain vital. First, GPs must retain the freedom to use their experience and apply an ever-expanding base of sound research findings to individual patient care, particularly those with complex comorbidities. ${ }^{9}$ (The Department of Health, however, prefers to see exception reporting as 'unacceptable'). ${ }^{10}$ Second, values remain vital. Without attention to ideals such as kindness, caring, good communication, honesty, and, above all, trust, the doctor-patient relationship is nothing ${ }^{11}$ and clinical outcomes - dependent on many things that hinge on the doctor-patient relationship, including the initial recognition of patients' problems, more accurate diagnosis, and concordance with treatment advice - may well begin to flounder. ${ }^{12,13}$

Although inherently difficult to measure, a number of qualitative studies (and numerous anecdotes) point to the QOF having negative effects in this area. In one survey, for example, $75.9 \%$ of nurses reported feeling the framework was undermining the patient focus of the NHS. ${ }^{14}$ The root cause of this is that the QOF has put an agenda in the clinicians' heads that is not necessarily consistent with the patients' perceptions: 'There have been one or two occasions where I went through the cholesterol, the depression, the CHD, and everything else', one GP reported,,$^{15}$ '... and the patient said "Well, what about my foot then?", "What foot?", I replied'. As one exploration into the impact of the QOF concluded:

'The QOF scheme may have achieved its declared objectives of improving disease-specific processes of patient care ... but our findings suggest that it has changed ... the nature of the practitioner-patient consultation. ${ }^{15}$

This is unlikely to be desirable - as those taking part in Gillies et al's study well recognise. The traditional strength of general practice is precisely its conscious effort to be open-ended, inclusive, personal, and relationship-building. Whatever use the QOF has in driving clinical quality, we should forever be aware of unintended consequences and remember the wisdom of the German physician Martin $\mathrm{H}$ Fischer nearly 100 years ago: 'In the sick room', he said, '10 cents worth of human understanding can equal 10 dollars' worth of medical science'. 


\section{James D Gubb}

Director of Health Unit, Civitas: The Institute for the Study of Civil Society, London, SW1P 2EZ. E-mail: james.gubb@civitas.org.uk

\section{Competing interests}

The author has stated that there are none.

\section{REFERENCES}

1. Iliffe S. From general practice to primary care: The industrialisation of family medicine. Oxford: Oxford University Press, 2008.

2. Gillies JCM, Mercer SW, Lyon A, et al. Distilling the essence of general practice: a learning journey in progress. Br J Gen Pract 2009; 59: el67-e176.

3. Gubb J, Li G. Checking-up on doctors: a review of the Quality and Outcomes Framework for general practitioners. London: Civitas, 2008.

4. Campbell S, Reeves D, Kontopantelis E, et al. Quality of primary care in England with the introduction of pay for performance. N Engl J Med 2007; 357(2): 181-190.

5. Doran T, Fullwood C, Kontopantelis E, Reeves D. Effect of financial incentives on inequalities in the delivery of primary clinical care in England: analysis of clinical activity indicators for the quality and outcomes framework. Lancet 2008; 372(9640): 728-736.

6. Howie JG, Heaney D, Maxwell M. Quality, core values and the general practice consultation: issues of definition, measurement and delivery. Fam Pract 2004; 21 (4): 458-468.

7. Steel N, Bachmann M, Maisey S, et al. Self reported receipt of care consistent with 32 quality indicators. BMJ 2008; $337:$ a957.

8. Steel N, Maisey S, Clark A, Fleetcroft R, Howe A. Quality of clinical primary care and targeted incentive payments: an observational study. Br J Gen Pract 2007; 57(539): 449-454.

9. Glasziou P, Burls A, Gilbert R. Evidence-based medicine and the medical curriculum: the search engine is now as essential as the stethoscope. BMJ 2008; 337 : a1253.

10. Department of Health. Developing the Quality and Outcomes Framework: proposals for a new, independent process (Consultation Response and Analysis). London: TSO, 2009.

11. Halligan, A, The importance of values in healthcare, J R Soc Med 2008: 101: 480-481.

12. Starfield B, Shi L, Macinko J. Contribution of primary care to health systems and health. Milbank Q 2005; 83(3): 457-502.

13. Adam R. 'Personal Care' and general practice medicine in the UK: a qualitative interview study with patients and general practitioners. Osteopath Med Prim Care 2007 ; 1 : 13.

14. Healthcare Republic. Independent Nurse QOF survey. http://www.healthcarerepublic.com/news/GP/772416/Independent-Nurse-QOF-survey/ (accessed 2 Apr 2009).

15. Campbell SM, McDonald R, Lester H. The experience of pay for performance in English family practice: a qualitative study. Ann Fam Med 2008; 6(3): 228-234.

DOI: 10.3399/bjgp09X420644

2. WONCA Europe. The European definition of general practice/family medicine. London: WONCA Europe, 2005.

3. Royal College of General Practitioners. Being a general practitioner. Curriculum statement 1. London: RCGP Publications, 2007.

4. Postgraduate Medical Education Training Board. http://www.pmetb.org.uk/ (accessed 12 Mar 2009).

5. Statutory Instrument 291. The National Health Service (general medical services contracts) regulations 2004: Sch.3. London: HMSO, 2004.

6. Roland M. Linking physicians' pay to the quality of care - a major experiment in the United Kingdom. N Engl J Med 2004; 351(14): 1448-1454.

7. Gillies John CM. Getting it right in the consultation. Hippocrates problem; Aristotle's answer. Occasional Paper 86. London, RCGP Publications, 2005.

8. Mangin D, Toop L. The Quality and Outcomes Framework: what have you done to yourselves? Br J Gen Pract 2007; 57(539): 435-437.

9. Heath I, Hippisley-Cox J, Smeeth L. Measuring performance and missing the point? BMJ 2007, 335(7629): 1075-1076.

10. Freeman G. Up close and personal? Continuing pressure on the doctor-patient relationship in the QOF era. Br J Gen Pract 2006; 56(528): 483-484.

11. Davies P, Glasspool J. Patients and the new contracts. BMJ 2003; 326(7399): 1099.

12. O'Dowd A. Devolution in health policy is threatening unity of the NHS. BMJ 2008; 336(7638): 241.

13. Greer S. Analysis: devolution and divergence in UK health policies. BMJ 2009; 338: 78-80.

14. International Futures Forum. http://www.internationalfuturesforum.com/ (accessed 30 Mar 2009).

15. Lyon A (compiler). The fifth wave, searching for health in Scotland. Edinburgh: Scottish Council Foundation, 2003.

16. The Homeless World Cup Centre. http://www3.homelessworldcup.org/ (accessed 12 Mar 2009).

17. Brown J, Isaacs D. World café conversations. The world café: shaping our futures through conversations that matter. San Frasncisco, CA:
Berrett-Koehler Publishers Inc, 2005.

18. RCGP Scotland. The essence of general practice. An invitation to create the future. http://www.rcgp.org.uk/bookshop/info_ 0000000000EGP.html (accessed 31 Mar 2009).

19. Hart JT. The political economy of health care. London: Policy Press, 2006.

20. Watt GCM. The NHS at 60: time to end the fairy tale. Br J Gen Pract 2008; 58(552): 459-460.

21. Hunter D. The health debate: policy and politics in the 21st century. Bristol: Policy Press, 2008.

22. Beckstrom O, Brafman R. The starfish and the spider: the unstoppable power of leaderless organisations. London: Portfolio Books, Penguin, 2008.

23. Gregory S. Learning specialist skills for a generalist discipline. Editorial. Br J Gen Pract 2009; 59(559): 79-80.

24. McWhinney I. The importance of being different. The Pickles lecture. Br J Gen Pract 1996; 46(408): 433-436.

25. Royal College of Physicians. Report of a Working Party. The doctor in society: medical professionalism in a changing world. London: RCP London, 2005.

26. Greenhalgh T. Thirty years on from Alma-Ata: where have we come from? Where are we going? The Pickles lecture. Br J Gen Pract 2008; 58(556): 798-804.

27. Heath I. The mystery of general practice. London: Nuffield Provinical Hospitals Trust, 1997.

28. Delamothe T. A good QOFing whine. BMJ 2008; 337: 1173.

29. Hunter KM. Narrative, literature and the clinical exercise of practical reason. J Med Philos 1996; 21(3): 303-320.

30. Tarrant C, Colman A, Stokes T. Past experience 'shadow of the future' and patient trust: a cross sectional survey. Br J Gen Pract 2008; 58(556): 780-783.

31. Freidson E. Professionalism: the third logic. On the practice of knowledge. Chicago, IL: University of Chicago Press, 2001.

32. Iliffe S. From general practice to primary care: the industrialization of family medicine. Oxford: Oxford University Press, 2008. 


\section{Appendix 1. Learning journeys.}

Figure 1 describes the elements and stages of the learning journey process which was used to help stimulate thinking and develop insights. Working together as a team in a learning journey to make sense of a difficult challenge provides powerful traction for further understanding and action. A learning journey begins with some colleagues agreeing to explore an important issue or challenge together. Having agreed on the issue to explore, they make site visits which might help to illuminate aspects of this challenge. Having made the visits they then reframe the challenge according to what they have learned. Figure 1 illustrates the stages in the process from issue identification, through site visits and reflection, to reframing the issue and associated policy and practice. The learning journey provides a focus for rapid learning and insight development. Site visits provide the basis of common focused experience around issues and concerns of interest - in this case the essence of general practice.

We live in a context of increasing complexity, rapid change, and uncertainty. While change is a common feature of life through the ages, there comes a time, every 250 years or so, when society and its institutions, values, memes, and mores undergo a more fundamental shift, a transformation. There is now a significant literature to suggest that we are currently living through such a time. In this soup of change, long-held ideas and beliefs do not work as well as they once did. While some of the current thinking, theories, and actions work well for straightforward problems, they work less well for rapidly emerging challenges and looming issues, such as shifting patterns of health and disease, climate change, persistent inequality, and governance. This raises the question of how to be effective in current times, when forms of organisation and practice designed for a world that no longer exists are less effective.

Successful learning journeys provide a way to approach this complexity. They usually include an experienced facilitator and support team. They include a range of field trips, usually, but not always, focused around a key theme or issue of interest, and are challenging to perception, mental models, and perspectives. Learning journeys are a good way to explore this present complexity to gain strategic insight about how to move forward on an issue. They help to unpack complexity and uncertainty through engagement. They surface and make explicit the assumptions that an individual or group holds. They can help to explore worldviews and mindsets in relation to important challenges from the outside in, by looking at the driving forces in the world at large, in the sector of operation, the organisation, and individual. This links learning journeys to the field of scenario planning. ${ }^{33}$ In particular learning journeys:

help to overcome the obstacles that normally get in the way of innovative thinking (for example, official versions of the future, existing mental models that don't include uncertainty, organisational hierarchy);

assist with the re-perception of risk and uncertainty, tapping into multiple intelligences and creativity; ${ }^{34}$

can help to develop discovery-driven planning that is effective in uncertain circumstances;

are effective, stimulating, and enjoyable in a variety of situations where a difficulty is proving intractable to already known approaches. Learning journeys usually help to develop understanding and approaches that are later useful in other situations.

\section{Learning journey 1}

In the work on the essence of general practice, the following types of organisations were initially visited:

a small local charity providing a daily lunch club for pensioners in a deprived peripheral estate;

a large international telecommunications and IT company, where a senior executive was interviewed.

The above two visits were planned to pilot the method for the essence of general practice group - would it prove a convivial method for us as a group? Would it provide useful insights? What could we learn from a pilot about how we might use the method subsequently? Participants were members of the essence steering group and the Director of Integrated Care at Glasgow Homeopathic Hospital. These two organisations were chosen because they were very different from each other and, in many respects, from general practice. In fact, the visits proved useful in highlighting that the issues that were explored in the essence of general practice group were very similar to concerns and issues being addressed in other walks of life.

\section{Learning journey 2}

This journey was focused on educators and trainees in general practice in South-East Deanery, NHS Education Scotland. All trainers were emailed (educational supervisors) and trainees in the deanery and they were asked to participate in a project designed to help 'develop an understanding of their work and the core values which inform and guide both the work and the practitioners'. Three trainees, four trainers, a researcher, and a facilitator took part.

This learning journey included sessions with:

the human resources department of a large NHS health board

the country director of a large financial institution

the director of an international homeless charity (Homeless World Cup). ${ }^{16}$

These visits were chosen to be diverse in their activities, approach to life, and aims and goals. Ostensibly different from general practice in organisation, motive, purpose, and intention, these visits raised a number of challenges to ideas about general practice; for example, what is unique about general practice? Discussion of these insights in subsequent debrief session, as well as detailed notes taken by two authors led to the key lessons in Box 2 , which are also reflected in Boxes 3 and 4.

\section{REFERENCES}

16. The Homeless World Cup Centre. http://www3.homelessworldcup.org/ (accessed 12 Mar 2009).

33. Van der Heijden K. Scenarios: art of strategic conversation. London: John Wiley and Sons, 1996.

34. Gardner H. Changing minds: the art and science of changing our own and other people's minds. Boston, MA: Harvard Business School Press, 2006. 


\section{Appendix 2. Discussion day and the '100 words' concept.}

Following the first learning journey, a discussion day for GPs was organised in Scotland under the title 'General practice: what sort of job; what sort of person?'. A 'world café conversation' model was used, ${ }^{18}$ designed to enable creative and wide-ranging discussion. Members of the steering group selected individuals to invite who would offer a wide variety of ideas and views on the subject. GPs were purposively selected from a variety of backgrounds remote and rural, inner city, academic, as well as GP directors of education, trainers, and trainees. Prominent UK thinkers in general practice were included, as well as a poet and a psychologist.

In all, 88 people were invited, and 40 attended, in addition to the steering group.

To stimulate discussion, some prominent UK GPs were commissioned to write 100 words, approximately, on general practice. The following idea was that of Professor Julian Tudor Hart:

'What I suggest is that you circulate a request to perhaps 10 to 20 GPs known for both original thought and action sustained through their professional lives, each to contribute their view of the most critical choices facing future students and educators creating GPs of the future, in not more than 100 words. These could be printed on cards including the authors' names (I think this would prompt more vigorous discussion), with a full set given to each participant. Ideally, they should get these before they arrive for the discussion so that they don't have to waste too much time reading them, can select what each thinks are the most important alternatives, and possibly develop their own 100-word statements.'

The steering group and Professor Tudor Hart asked 27 doctors to write 100 words. Seventeen replied; one has since asked that his contribution not be included. An example is:

The most critical choices facing future students and educators creating GPs of the future

Three key choices for educators

- 'Behaviourist' versus 'humanist' philosophy. Do we focus on improving performance against objectively measurable indicators or on developing professional virtues which can only ever be measured indirectly and subjectively? And if 'a bit of both', what is the most appropriate balance?

- Educator's role. In all areas of education, there is a move from 'sage on the stage' to 'guide on the side' and perhaps even 'host on the post'.

- Medium. High-tech versus low-tech? How and to what extent might online methods (universally accessible, timeless, spaceless, archivable, potentially image-rich and multi-channel) replace and/or supplement face-to-face meetings ('high bandwidth' interaction that everyone understands)?

These were sent to participants in advance, and also displayed prominently in the room on the day for reference.

The setting, a restaurant in a theatre in Glasgow, was chosen deliberately not to be associated with medicine, to encourage original thinking and free association of ideas.

The day started with short (3-4 minutes) personal reflections on general practice from four individuals (three of the authors and Dr Euan Patterson), summarised in the RCGP learning tools, ${ }^{18}$ and was facilitated by Andrew Lyon from the International Future Forum. An initial plenary discussion was followed by 'café conversations' - small groups set up to explore issues more deeply. Group members were rotated twice during the day, which finished with a plenary session. Data were gathered in several ways. The plenary sessions were digitally recorded. Participants wrote ideas on paper tablecloths as they developed, and these were analysed and summarised. These were combined into a single report circulated to participants.

Subsequently we asked the RCGP Scotland Patient Participation Group to write 100-word statements on the related questions:

What do you value from your GP?

What do you see as the unique role of your GP?

The group comprises five lay members and two GPs. (The GPs wrote on 'What do I value about being a GP?' and 'What do I see as the unique role of a GP?'.)

An example is given below, from a lay member: What do you value from your GP?

'I value the fact that, when talking to my GP, he is open and truthful, empathetic, and will listen to suggestions that I put forward regarding treatment for my condition. It is teamwork.'

'What I value: time; sympathetic and caring (but also humour); gives me confidence to manage things myself; never makes me feel I am wasting his time; I have confidence in him because he never pretends to know everything and will stop to check things (for example, dosages) if unsure. I respect him for that. A good listener, unhurried. Continuity of care so we have built up a relationship.'

'I value most of all the time my GP gives me, the level of understanding and interest around my health and life issues, also other qualities such as, patience, an alternative perspective, support, encouragement, and trust.'

'My GP takes time to explain things to me, draws diagrams, etcetera. He is prepared to accept what I say about adverse reactions to prescriptions and change them if necessary.'

The sections 'Learning from the journey' and 'Defining the essence of general practice: the journey continues' summarise key findings from the learning journeys, the 100 words, and the discussion day. 